\title{
Tourniquet-Induced Sciatic Nerve Injury: An Unusual Complication of Coronary Artery Bypass Graft Surgery
}

\author{
Shin C. Beh, MD* \\ Department of Neurology, University of Texas Southwestern Medical Center, Dallas, Texas, USA
}

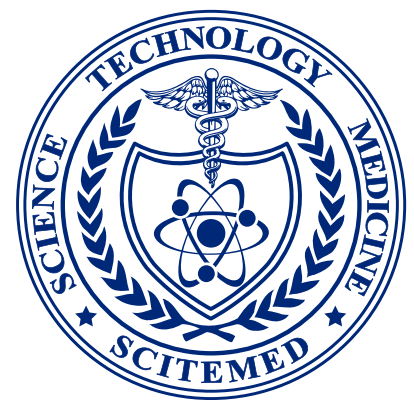

\begin{abstract}
A 53-year-old man with hypertension underwent coronary artery bypass grafting. Following surgery, he developed left leg numbness and weakness. Examination revealed left sciatic neuropathy, as well as a circumferential lesion over the left mid-thigh which was revealed to be due to a surgical tourniquet. He was diagnosed with tourniquet-induced left sciatic neuropathy, and by the end of his hospitalization, recovered full strength and sensation in his left lower extremity.
\end{abstract}

\section{Case Report}

A 53-year-old man was evaluated for left lower extremity weakness and numbness after undergoing coronary artery bypass graft (CABG) surgery. He denied any history that would suggest peripheral neuropathy.

His examination revealed weakness of left knee flexion (Medical Research Council grade 3/5), dorsiflexion (1/5), plantarflexion (3/5), foot eversion (2/5), foot inversion (3/5), toe-extension (2/5), and toe-flexion (3/5), with preserved strength of hip flexors, hip extensors, knee extensors, hip abductors, and hip adductors. The Achilles reflex was absent but the patellar reflex was intact. Sensation was diminished over the

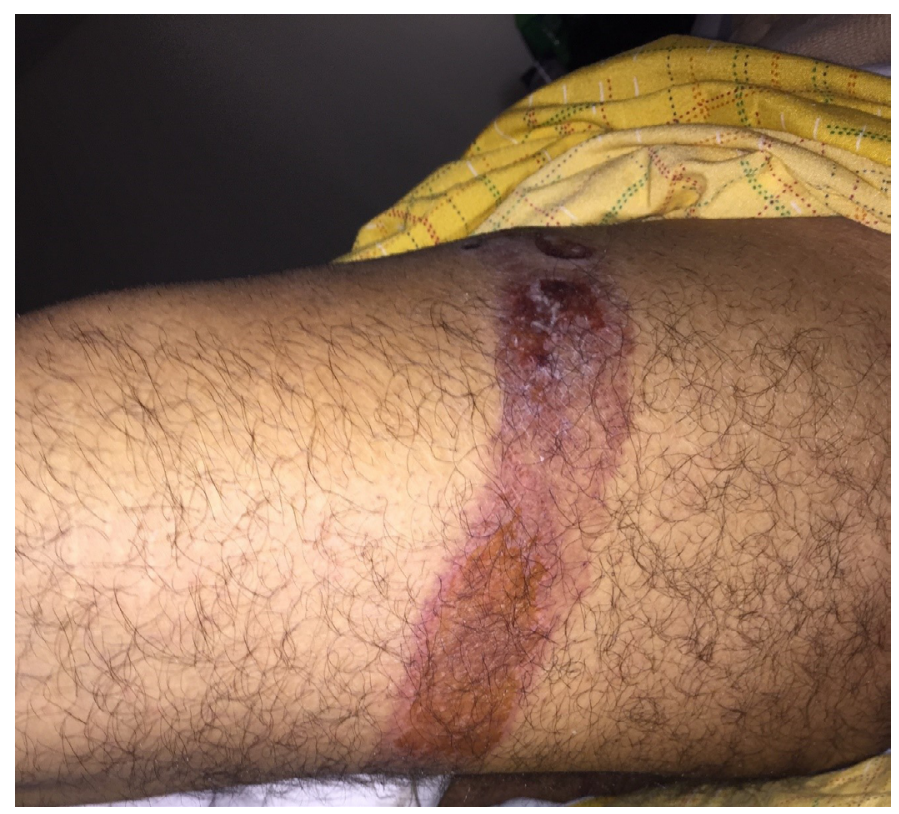

Figure 1. A well-circumscribed, circumferential, purplish lesion with focal blistering over the left mid-thigh indicated the location where a tourniquet was placed during greater-saphenous vein harvesting during this patient's surgery. outer aspect of his leg, foot dorsum, and sole. These findings were consistent with left sciatic neuropathy. Interestingly, a well-circumscribed, circumferential, purplish lesion with focal superficial lacerations (Figure 1) was observed over the left mid-thigh. Further investigation revealed that a tourniquet was placed over this exact area for approximately 2.5 hours during surgery to minimize bleeding while harvesting the greater saphenous vein.

With this information, he was diagnosed with tourniquet-induced left sciatic neuropathy. Electromyography and nerve conduction studies were not performed immediately post-operatively since electrophysiologic changes only occur 7-10 days following nerve injury. His strength gradually improved with physical therapy, and by the end of his stay two weeks later, he had full recovery of strength.

\section{Discussion}

Torniquet-induced injuries of the sciatic nerve are rare, but its risk increases with prolonged tourniquet time during surgery $[1,2]$. Most reported cases have occurred in knee arthroplasty $[1,2]$. While tourniquets are used to harvest the saphenous vein for CABG surgery [3], to my knowledge, there have been no reported cases of tourniquet-induced sciatic neuropathy arising from tourniquet usage in CABG.

Since the sciatic nerve divides in the posterior mid-thigh to form the common peroneal and tibial nerves, pneumatic tourniquets placed around the thigh (to minimize bleeding during lower-limb surgery) may cause compressive common peroneal, sciatic, and tibial neuropathies, presumably from a combination of mechanical trauma and ischemic insult $[1,2]$. The majority are transient neuropraxic injuries, but in some, the deficits are permanent $[1,2]$. Prolonged tourniquet time significantly increases the risk of such injuries, and as such, should be released at set intervals to allow reperfusion [2]. It is very possible that the vascular risk factors that resulted in this patient requiring CABG increased his risk of developing tourniquet-induced sciatic neuropathy. The role of vascular risk factors in tourniquet-related nerve injuries needs to be investigated further.

\section{Conclusion}

Neurologists should be aware of tourniquet-induced injury as a possible etiology of post-operative nerve palsies. 


\section{CASE REPORT}

Article Information

*Correspondence: Shin C. Beh, MD

Department of Neurology, University of Texas Southwestern Medical Center, 5323 Harry Hines Blvd, Dallas, TX 75390. USA. Email: shin.beh@utsouthwestern.edu

Received:Jul. 02, 2018; Accepted:Jul. 10, 2017; Published: Aug. 07, 2018

DOI: 10.24983/scitemed.nnr.2018.00074

Copyright (c) 2018 The Author(s). This is an open-access article distributed under the terms of the Creative Commons Attribution 4.0 International License (CC-BY).

\section{Funding: None}

\section{Conflict of Interest: None}

\section{Keywords}

Sciatic nerve; sciatic neuropathy; tourniquet.

\section{References}

1. Schinsky MF, Macaulay W, Parks ML, Kiernan $H$, Nercessian OA. Nerve injury after primary total knee arthroplasty. J Arthroplasty 2001;16(8):1048-1054.

2. Horlocker TT, Hebl JR, Gali B, et al. Anesthetic, patient, and surgical risk factors for neurologic complications after prolonged total tourniquet time during total knee arthroplasty. Anesth Analg 2006;102(3):950-955.

3. Cohn JD, Korver KF. Optimizing saphenous vein site selection using intraoperative venous duplex ultrasound scanning. Ann Thorac Surg 2005;79(6):2013-2017. 